\title{
Risk prediction tool for use and predictors of duration of postoperative oxygen therapy in children undergoing non-cardiac surgery: a case-control study
}

Maliwan Oofuvong ${ }^{*}$ (D), Siriwimol Ratprasert and Thavat Chanchayanon

\begin{abstract}
Background: We aimed to construct a prediction tool for postoperative oxygen therapy and determine predictors of duration of use among children undergoing non-cardiac surgery.

Methods: Data from this case-control study was obtained from a database of 9820 children aged < 15 years who underwent general anesthesia between January 2010 and December 2013 at a tertiary care hospital in southern Thailand. The primary outcomes were the use and duration (hours) of postoperative oxygen therapy (cases). Cases were matched with controls on age group and year of surgery in a ratio of 1:4. A negative binomial hurdle model was used to obtain significant predictors of any use and number of hours of oxygen therapy. A risk score was derived from the coefficients of the significant predictors. The risk score, adjusted odds ratio (OR) for any use and count ratio (CR) for duration of postoperative oxygen therapy and $95 \%$ confidence interval (Cl) were determined.

Results: A total of 288 cases and 1152 controls were included. The median (inter-quartile range) duration of oxygen therapy delivered was 17 (9-22) hours. An optimal risk score for predictors of oxygen use was 12 (0-32) giving an area under the receiver operating characteristic curve of 0.93 . Predictors of high risk need for oxygen therapy (score $\geq 12)$ were thoracic surgery $(\mathrm{OR}=278,95 \% \mathrm{Cl}=44.6-1733)$ and having desaturation perioperatively $(\mathrm{OR}=459.8,95 \% \mathrm{Cl}=169.7-1246)$. Intermediate risk factors (score 8-11) were having bronchospasm (OR $=92.4$, $95 \% \mathrm{Cl}=29.7-287.5)$ and upper airway obstruction/laryngospasm $(\mathrm{OR}=61.5,95 \% \mathrm{Cl}=14.4-262.4)$ perioperatively. Significant predictors of duration of oxygen therapy were probably difficult airway $(C R=2.2,95 \% \mathrm{Cl}=1.4-3.5)$, history of delayed development $(C R=2.3,95 \% \mathrm{Cl}=1.5-3.6)$, airway $(C R=3.0,95 \% \mathrm{Cl}=1.6-5.8)$, orthopedic $(C R=2.1$, $95 \% \mathrm{Cl}=1.1-4.3)$, thoracic $(C R=4.9,95 \% \mathrm{Cl}=2.3-10.1)$ and abdominal surgery $(C R=4.2,95 \% \mathrm{Cl}=2.1-8.1)$, compared to eye surgery.

Conclusions: Our risk prediction tool for the use of postoperative oxygen therapy provided a high predictive ability. Children who have thoracic surgery, desaturation, bronchospasm, upper airway obstruction or laryngospasm will most likely need postoperative oxygen therapy, regardless of other factors, while those with a probably difficult airway, history of delayed development, or thoracic/abdominal surgery will most likely need longer duration of oxygen therapy.
\end{abstract}

Keywords: Predictors, Duration of use, Postoperative oxygen therapy, Pediatric anesthesia

\footnotetext{
* Correspondence: oomaliwa@gmail.com

Department of Anesthesiology, Faculty of Medicine, Prince of Songkla

University, 15 Kanjanavanich Road, Songkhla 90112, Thailand
}

(c) The Author(s). 2018 Open Access This article is distributed under the terms of the Creative Commons Attribution 4.0 International License (http://creativecommons.org/licenses/by/4.0/), which permits unrestricted use, distribution, and reproduction in any medium, provided you give appropriate credit to the original author(s) and the source, provide a link to the Creative Commons license, and indicate if changes were made. The Creative Commons Public Domain Dedication waiver (http://creativecommons.org/publicdomain/zero/1.0/) applies to the data made available in this article, unless otherwise stated. 


\section{Background}

At the post-anesthetic care unit (PACU), postoperative oxygen therapy is often given to patients, particularly children, after finishing general anesthesia. Studies have shown that general anesthesia, which induces airway closure, ventilation, and perfusion mismatch, can decrease the functional residual capacity causing hypoxemia and necessitates supplemental oxygen during the first postoperative hour that continues into the postoperative period [1-5]. Since the prevalence of hypoxemia at the PACU in children can be as high as $21 \%$ [5], supplemental oxygen therapy during transfer to the PACU [6] and throughout the PACU stay is recommended [7].

Despite the usefulness of oxygen therapy, longer use of postoperative oxygen therapy can be harmful to children [8]. In addition, surgery-related or anesthesia-related factors may also be important. However, a risk prediction tool for the need of postoperative oxygen therapy in children has never been developed and predictors of the duration and use of postoperative oxygen therapy in children have not been determined. Therefore, the objectives of this study were to develop a risk prediction tool for postoperative oxygen therapy and to determine predictors of duration of use in children undergoing non-cardiac surgery with general anesthesia. The results of this study may help guide anesthesia personnel determine which patient groups are more likely to require postoperative oxygen therapy as well as those who may require longer use.

\section{Methods}

This was a matched case-control study among children who underwent non-cardiac surgery at Songklanagarind Hospital which is an 853-bed tertiary care university hospital in southern Thailand. The study was approved by the Institutional Ethics Committee of the Faculty of Medicine, Prince of Songkla University, Songkhla, Thailand (Chairperson Assoc. Prof. Boonsin Tangtrakulwanich) on October 8, 2014 [EC57294081].

\section{Participants}

The surveillance anesthetic database under quality assurance conference by nurse anesthetists performed every 2 months was used to identify children aged less than 15 years who received postoperative oxygen therapy after undergoing non-cardiac surgical procedures as well as digital imaging or other interventions under general anesthesia with or without regional anesthesia or peripheral nerve block between January 2010 and December 2013. All identified children were confirmed eligible by chart review of electronic anesthetic records by two investigators $(\mathrm{MO}, \mathrm{SR})$. Patients were excluded if they were classified as American Society of Anesthesiologists
(ASA) physical status 4 or 5 , had preoperative oxygen saturation by pulse oximetry $\left(\mathrm{SpO}_{2}\right)<95 \%$ at room air, received preoperative oxygen therapy, were endotracheally intubated, or their lungs were mechanically ventilated or both before or after surgery, had congenital cyanotic heart disease, or had cardiac surgery. These criteria were used to exclude pre-existing active respiratory problems before surgery or cardiopulmonary problems after surgery. The children who needed postoperative mechanical ventilation have more severe respiratory insufficiency and may have different risk factors compared to children who need only postoperative oxygen and were therefore excluded from the study.

\section{Anesthetic practice and standard operating procedure [9]}

The choice of anesthesia, anesthetic agents, and type of airway devices were made by a certified anesthesiologist. The decision to give general anesthesia combined with epidural analgesia, caudal block, or peripheral nerve block was made by a certified anesthesiologist with at least 1 year experience. There were on average 18 certified anesthesiologists per year during the four-year study period. The anesthetic resident and anesthetic nurse observed children from induction until discharge from the recovery room under supervision of staff anesthesiologists. At the end of the operation, children were transferred either to the PACU or pediatric intensive care unit. Children who had $\mathrm{SpO}_{2}<95 \%$ would receive $100 \%$ oxygen via facemask during transfer to the PACU. Children who received massive transfusion, or had potential cardiovascular or respiratory problems were transferred to the pediatric intensive care unit to continue intubation with mechanical ventilation.

At the PACU, anesthetic nurses gave an oxygen facemask (aerosol mask) via high flow air/oxygen blender with a dial setting at fractional inspired oxygen 0.4 up to 0.6. The flow rate was adjusted depending on the patient's respiratory pattern to achieve fractional inspired oxygen at the set point. If a patient refused to wear an oxygen facemask, oxygen insufflation was performed by blowing into the patient's nostrils and mouth. Low flow oxygen via nasal cannula is rarely used because it causes nasal discomfort and more humidity is needed. Oxygen therapy via oxygen facemask was continued at the pediatric ward depending on the discretion of the anesthesiologist based on three conditions. First, in some high-risk patients, such as those with obstructive sleep apnea syndrome or prolonged operation, oxygen therapy was not discontinued. Second, after oxygen therapy was discontinued, oxygen therapy was reinstituted in case of dyspnea, having respiratory events, or if $\mathrm{SpO}_{2}$ fell below $95 \%$. Third, in case of suspected upper airway edema, the patient was endotracheally intubated with spontaneous breathing via oxygen $\mathrm{T}$-piece. 


\section{Outcome of interest}

\section{Postoperative oxygen therapy}

Postoperative oxygen therapy was defined when patients were given postoperatively an oxygen facemask, oxygen insufflation, or oxygen T-piece at the PACU and pediatric ward. Children who did not immediately receive postoperative oxygen but required oxygen at or after postoperative day 1 or needed postoperative mechanical ventilation were excluded at the beginning of the study process and were not included in the analysis. Use of postoperative oxygen therapy was retrieved from the validated anesthetic records by two investigators (MO, SR) and confirmed by the nurses' notes from the hospital information system. Children who were given postoperative oxygen therapy were defined as cases and each case was randomly matched with four patients who were not given postoperative oxygen therapy (controls). The four controls increased the power of the study due to the low number of cases.

\section{Duration of postoperative oxygen therapy}

Oxygen saturation by pulse oximetry was continuously monitored during oxygen therapy. Weaning off oxygen therapy was attempted at the pediatric ward when the patient had no signs or symptoms of respiratory disturbance, or the $\mathrm{SpO}_{2}$ reached 95\% while the patient was breathing room air. The duration of postoperative oxygen therapy in hours was defined from the time of starting oxygen therapy at the PACU until terminating oxygen therapy and the patient could breathe spontaneously. This information was retrieved from the nurses' notes from the electronic hospital information system. The start and stopping dates of oxygen therapy were recorded by agreement of the two investigators (MO, SR).

\section{Matching procedure}

All cases were identified from the anesthetic records and the hospital information system according to the above-mentioned criteria. To avoid selection bias and imbalance between cases and controls, a matching algorithm was constructed. The list of controls was selected from the pool of patients kept in the department of pediatrics database. Data management with application of the exclusion criteria was managed by MO to accomplish the qualified controls. Each case was randomly matched with four qualified controls based on age group $(<1,1-6,>6$ years $)$ and year of operation.

\section{Potential predictors and confounding variables}

Covariates were categorized into 11 patient-related factors, two surgery-related factors (elective/emergency and site of procedure), seven anesthesia-related factors, and occurrence of respiratory events during anesthesia. Patient-related factors included sex, body mass index $\left(\mathrm{kg} / \mathrm{m}^{2}\right)$, history of upper respiratory tract infection (URI) (defined as any sign or symptom of rhinitis, cough, pharyngitis, or an active or recent URI within 2 weeks), history of hyper-reactive airway (defined as a history of allergic rhinitis or asthma), history of pulmonary disease (defined as a history of pneumonia, atelectasis, or bronchiectasis within 2 weeks), history of snoring, history of non-cyanotic heart disease, history of delayed development (defined as a history of cerebral palsy or mental retardation), preoperative anemia (males and females having a hemoglobin below $13 \mathrm{~g} / \mathrm{dl}$ and $12 \mathrm{~g} / \mathrm{dl}$, respectively), having a probable difficult airway, and having a risk of aspiration (defined as inadequate nothing-by-mouth time, full stomach, or history of gastroesophageal reflux) (Table 1). Anesthesia-related factors included ASA physical status, choice of anesthesia, airway device, neuromuscular blocking agent used, volatile anesthetic agent used, narcotic used, and anesthetic time (Table 2). A respiratory event during anesthesia was defined as having an event such as laryngospasm (defined as a partial or complete upper airway obstruction from a spasm of the vocal cords), upper airway obstruction (defined as soft tissue obstruction or secretion obstruction after the airway device was removed), bronchospasm (defined as a lower airway obstruction from a spasm of bronchial smooth muscle) or wheezing, or desaturation $<95 \%$ for at least $10 \mathrm{~s}$ [10] during the intraoperative period or at the PACU.

\section{Statistical analysis}

All variables are presented descriptively with mean and standard deviation or median and interquartile range as appropriate for continuous variables, and frequency and percent for categorical variables. Unpaired Student's t-tests or Wilcoxon's rank sum tests were used to compare normally or non-normally distributed variables, respectively, between the two outcome groups. The chisquare test or Fisher's exact test was used to compare categorical variables. Predictors of the use and duration of postoperative oxygen therapy were determined using a hurdle model with adjustment for potential confounders $[11,12]$. The hurdle model had two sets of predictors. The first set predicted whether the patient used any oxygen therapy postoperatively. The second set predicted the duration of oxygen therapy among the cases. The model was refined by sequential backward elimination of non-significant variables performed by the likelihood ratio test that provided coefficients and their 95\% confidence intervals. The exponential of these coefficients gave adjusted odds ratios to assess the effects of various factors on any oxygen therapy and adjusted count ratios to assess the multiplying effects of various factors on duration (hours) of oxygen therapy. Factors were considered significant if the likelihood ratio test $p$ values were $<0.05$. 
Table 1 Demographic data among children who received postoperative oxygen therapy compared with those who did not

\begin{tabular}{|c|c|c|c|}
\hline Factor & $\begin{array}{l}\text { No oxygen therapy } \\
(n=1152)\end{array}$ & $\begin{array}{l}\text { Oxygen therapy } \\
(n=288)\end{array}$ & $p$ value \\
\hline Age (years) & & & 0.99 \\
\hline$<1$ & $216(18.8)$ & $54(18.8)$ & \\
\hline $1-6$ & $552(47.9)$ & $138(47.9)$ & \\
\hline$>6$ & $384(33.3)$ & $96(33.3)$ & \\
\hline Male & $684(59.4)$ & $182(63.2)$ & 0.26 \\
\hline Weight, median (IQR) (kg) & $16.0(9.8-25.0)$ & $14.3(8.4-33.4)$ & 0.41 \\
\hline Height, median (IQR) (cm) & $104.0(80-128.0)$ & $98.5(75.0-130.0)$ & 0.19 \\
\hline Body mass index $\left(\mathrm{kg} / \mathrm{m}^{2}\right)$ & & & $<0.001^{*}$ \\
\hline $5-14.9$ & 479 (41.6) & $130(45.1)$ & \\
\hline $15-24.9$ & $629(54.6)$ & $128(44.4)$ & \\
\hline $25-60$ & $44(3.8)$ & $30(10.4)$ & \\
\hline URI (Y/N) & $72(6.2) / 1080$ (93.8) & $23(8) / 265(92.0)$ & 0.35 \\
\hline Pulmonary disease (Y/N) & $8(0.7) / 1144(99.3)$ & $16(5.6) / 272(94.4)$ & $<0.001^{*}$ \\
\hline Hyper-reactive airway (Y/N) & $65(5.6) / 1087(94.4)$ & $24(8.3) / 264(91.7)$ & 0.12 \\
\hline Anemia $(\mathrm{Y} / \mathrm{N})$ & $526(45.7) / 626(54.3)$ & $127(44.1) / 161(55.9)$ & 0.68 \\
\hline Snoring $(\mathrm{Y} / \mathrm{N})$ & $14(1.2) / 1138(98.8)$ & $4(1.4) / 284(98.6)$ & 0.95 \\
\hline Non-cyanotic heart (Y/N) & $41(3.6) / 1111(96.4)$ & $30(10.4) / 258(89.6)$ & $<0.001^{*}$ \\
\hline Probable difficult airway (Y/N) & $12(1.0) / 1140(99.0)$ & $21(7.3) / 267(92.7)$ & $<0.001^{*}$ \\
\hline Risk of aspiration (Y/N) & $24(2.1) / 1128(97.9)$ & $11(3.8) / 277(96.2)$ & 0.13 \\
\hline Delayed development (Y/N) & $34(3.0) / 1118(97.0)$ & $22(7.6) / 266(92.4)$ & $<0.001^{*}$ \\
\hline
\end{tabular}

Data are presented as frequency (percentage) unless otherwise stated

* $<0.05$ by chi-squared test

$I Q R$ inter-quartile range, URI Upper respiratory tract infection

\section{Hurdle model}

Hurdle models are one type of regression model for count data that can handle zero inflated outcomes, i.e., many zero observations. There are two-components in the modeling process: a truncated count component which is often modeled using a Poisson or negative binomial distribution for non-zero counts (in this study the number of hours of postoperative oxygen therapy), and a hurdle component which models the probability of a zero count, i.e., no oxygen therapy, versus non-zero count, i.e., use of oxygen. The zero count process is modeled using logistic regression. Due to over-dispersion, i.e., a situation where the variance is much larger than the mean, in the number of hours of oxygen therapy and the fact that many children in our study did not receive oxygen therapy, a negative binomial hurdle model was chosen for this analysis. This distribution also fit our data better than the Poisson model.

The hurdle model is given by the following equation:

$$
\mathrm{f}_{\text {hurdle }}(y ; x, z, \beta, \gamma)= \begin{cases}\mathrm{f}_{\text {zero }}(0 ; z, \gamma), & \text { if } y=0 \\ \left(1-\mathrm{f}_{\text {zero }}(0 ; z, \gamma)\right) \times \frac{\mathrm{f}_{\text {count }}(y ; x, \beta)}{1-\mathrm{f}_{\text {count }}(0 ; x, \beta)}, & \text { if } y>0\end{cases}
$$

$y=$ outcome (number of hours of postoperative oxygen therapy) $x=$ potential predictors of the truncated count data model

$z=$ potential predictors of the zero hurdle model

$\beta=$ vector of regression coefficients of $\mathrm{f}_{\text {count }}$

$\gamma=$ vector of regression coefficients of $\mathrm{f}_{\text {zero }}$

The regression coefficients are estimated using maximum likelihood. The corresponding mean regression relationship is given by:

$$
\begin{aligned}
\log \left(\mu_{\mathrm{i}}\right)=x_{\mathrm{i}}^{\mathrm{T}} \beta & +\log \left\{1-\mathrm{f}_{\text {zero }}\left(0 ; z_{\mathrm{i}}, \gamma\right)\right\} \\
& -\log \left\{1-\mathrm{f}_{\text {count }}\left(0 ; x_{\mathrm{i}}, \beta\right)\right\}
\end{aligned}
$$

where $\mu_{\mathrm{i}}=$ mean number of hours using oxygen.

\section{Risk prediction tool}

The risk prediction tool was developed using the first set of predictors from the hurdle model. A test for discrimination was used to attain the predictive accuracy of the tool. The risk score of postoperative oxygen therapy was calculated from the coefficients of the significant covariates in the final model [13]. Scores were obtained by multiplying each coefficient by 2 and then rounding the result to the nearest integer for simple interpretation. Model discrimination performance was examined using 
Table 2 Anesthesia- and surgical-related risk among children who received postoperative oxygen therapy compared with those who did not

\begin{tabular}{|c|c|c|c|}
\hline Factor & $\begin{array}{l}\text { No oxygen therapy } \\
(n=1152)\end{array}$ & $\begin{array}{l}\text { Oxygen therapy } \\
(n=288)\end{array}$ & $p$ value \\
\hline ASA physical status & & & $<0.001^{*}$ \\
\hline 1 & $242(21.0)$ & $21(7.3)$ & \\
\hline 2 & $742(64.4)$ & $136(47.2)$ & \\
\hline 3 & $168(14.6)$ & $131(45.5)$ & \\
\hline Type of case & & & $<0.001^{*}$ \\
\hline Elective & $984(85.4)$ & $212(73.6)$ & \\
\hline Emergency & $168(14.6)$ & $76(26.4)$ & \\
\hline Site/ type of procedure & & & $<0.001^{*}$ \\
\hline Eye & $226(19.6)$ & $11(3.8)$ & \\
\hline Urologic & $212(18.4)$ & $33(11.5)$ & \\
\hline Airway & $187(16.2)$ & $66(22.9)$ & \\
\hline Ear-nose-face & $93(8.1)$ & $19(6.6)$ & \\
\hline Thoracic & $2(0.2)$ & $23(8.0)$ & \\
\hline Intra-abdomen & $84(7.3)$ & $49(17.0)$ & \\
\hline Orthopedic & $238(20.7)$ & $50(17.4)$ & \\
\hline Intra-cranial & $14(1.2)$ & $9(3.1)$ & \\
\hline Gastrointestinal scope & $53(4.6)$ & $13(4.5)$ & \\
\hline Cardiac catheterization & $43(3.7)$ & $15(5.2)$ & \\
\hline Choice of anesthesia & & & $0.04^{*}$ \\
\hline GA only & $948(82.3)$ & $252(87.5)$ & \\
\hline GA with epidural/caudal & $151(13.1)$ & $31(10.8)$ & \\
\hline GA with peripheral nerve block & $53(4.6)$ & $5(1.7)$ & \\
\hline Airway device & & & $<0.001^{*}$ \\
\hline Facemask/laryngeal mask airway & $411(35.7)$ & $31(10.8)$ & \\
\hline Spontaneous breathing with non-rebreathing mask & $28(2.4)$ & $4(1.4)$ & \\
\hline Endotracheal tube intubation & $713(61.9)$ & $253(87.8)$ & \\
\hline Neuromuscular blocking agent & & & $<0.001^{*}$ \\
\hline Succinylcholine & $84(7.3)$ & $45(15.6)$ & \\
\hline Aminosteroid derivatives & $39(3.4)$ & $29(10.1)$ & \\
\hline Benzylisoquinolines & $456(39.6)$ & $141(49.0)$ & \\
\hline None & $573(49.7)$ & $73(25.3)$ & \\
\hline Inhalation agent & & & 0.99 \\
\hline Sevoflurane & $945(82.0)$ & $236(81.9)$ & \\
\hline Desflurane & $24(2.1)$ & $6(2.1)$ & \\
\hline None & $183(15.9)$ & $46(16.0)$ & \\
\hline Narcotic & & & $0.006^{*}$ \\
\hline Fentanyl & $841(73.0)$ & $204(70.8)$ & \\
\hline Morphine & $100(8.7)$ & $42(14.6)$ & \\
\hline None & $211(18.3)$ & $42(14.6)$ & \\
\hline Anesthetic time (hour) & & & $<0.001^{*}$ \\
\hline$<1$ & $281(24.4)$ & $27(9.4)$ & \\
\hline $1-<3$ & 737 (64.0) & $201(69.8)$ & \\
\hline$\geq 3$ & $134(11.6)$ & $60(20.8)$ & \\
\hline
\end{tabular}


Table 2 Anesthesia- and surgical-related risk among children who received postoperative oxygen therapy compared with those who did not (Continued)

\begin{tabular}{lll}
\hline Factor & $\begin{array}{l}\text { No oxygen therapy } \\
(n=1152)\end{array}$ & $\begin{array}{l}\text { Oxygen therapy } \\
(n=288)\end{array}$ \\
\hline PRAE & $1,130(98.1)$ & $129(44.8)$ \\
None & $0(0)$ & $9(3.1)$ \\
Upper airway obstruction & $9(0.8)$ & $3(1.0)$ \\
Laryngospasm & $7(0.6)$ & $126(43.8)$ \\
Desaturation & $6(0.5)$ & $21(7.3)$ \\
Bronchospasm/wheezing & &
\end{tabular}

Data are presented as frequency (percentage) unless otherwise stated

* $<0.05$ by chi-squared test

ASA American Society of Anesthesiologists, GA General anesthesia, PRAE Perioperative respiratory adverse events

the area under the receiver operating characteristic (ROC) curve providing sensitivity and specificity based on the optimal cut-point of the risk score.

\section{Sample size determination}

We estimated the lowest prevalence of exposure (potential predictor) among the controls to be $5 \%$ with a ratio of controls to cases of $4: 1$ to detect an odds ratio of at least 2.0 using a significance level of 0.05 and a power of $80 \%$ that resulted in a required sample size of 250 cases and 1000 controls. The mean prevalence of postoperative oxygen therapy among non-cyanotic children in our hospital between 2010 and 2013 was 3\%. Therefore, 4 years of retrospective data were required to obtain this sample size.

\section{Results}

From the database, 9614 children received general anesthesia during the four-year study period. After applying the exclusion criteria, 8044 children were eligible for the study. Figure 1 shows the flow diagram of the study which contained 288 cases and 1152 matched controls. Five percent of height data were missing and replaced by the mean height of children of the same age and sex. The reasons for giving postoperative oxygen therapy were prophylaxis in high risk patients or high risk operations (43.8\%), perioperative desaturation (44.4\%), perioperative wheezing/ rhonchi (4.5\%), spontaneous breathing via T-piece (3.8\%), perioperative upper airway obstruction (2.4\%), and shivering $(1 \%)$. Some children $(<50 \%)$ who had either a probable difficult airway or airway surgery were endotracheally intubated and received oxygen via the T-piece connector. Table 1 compares the demographic data of children who received postoperative oxygen therapy to those who did not. High body mass index, history of pulmonary disease, history of non-cyanotic heart disease, having a probable difficult airway, and history of delayed development were significantly different between the two groups. Table 2 shows a similar comparison of anesthesia-related and surgery-related risk factors. There were significant differences between the two groups in terms of ASA physical status, elective/emergency case, site and type of surgery, choice of anesthesia, airway device, neuromuscular blocking agents used, narcotic used, anesthetic time, and having a respiratory event during anesthesia.

\section{Analysis of postoperative oxygen therapy}

Seven variables having a $p$ value $\leq 0.2$ from the univariate analysis were included in the initial multivariate hurdle model but were not significant: history of pulmonary disease, history of non-cyanotic heart disease, history of delayed development, having risk of aspiration, elective/ emergency, choice of anesthesia, and narcotic used. Table 3 shows the results of the final hurdle model predicting postoperative oxygen therapy.

\section{Development of risk prediction tool}

Risk scores from the model are shown in Table 3. We selected the reference group based on the subgroup which had a lowest risk. The scores were summed to obtain an individual risk score which ranged from 0 to 32. Figure 2 shows the ROC curve of the individual risk scores predicting oxygen therapy. The area under the curve was 0.93 and the optimal cut-point based on the highest summation of sensitivity (85\%) and specificity (86\%) of the model was 12 . The risk scores were then classified into three groups: high $(\geq 12)$, intermediate $(8-11)$, and low $(\leq 7)$ that indicated the level of need for postoperative oxygen therapy.

\section{Duration of postoperative oxygen therapy}

The median (inter-quartile range) duration of oxygen therapy among the cases was $17 \mathrm{~h}$ (range 9-22 h). The distribution of the number of hours of oxygen use was over-dispersed, thus using a negative binomial hurdle model fit the data much better than the Poisson hurdle model (Additional file 1). Nine variables that had a $p$ value $\leq 0.2$ in the univariate analysis were included in the initial multivariate hurdle model but were not significant: body mass index, history of URI, history of pulmonary disease, history of snoring, anemia, choice of anesthesia, airway 


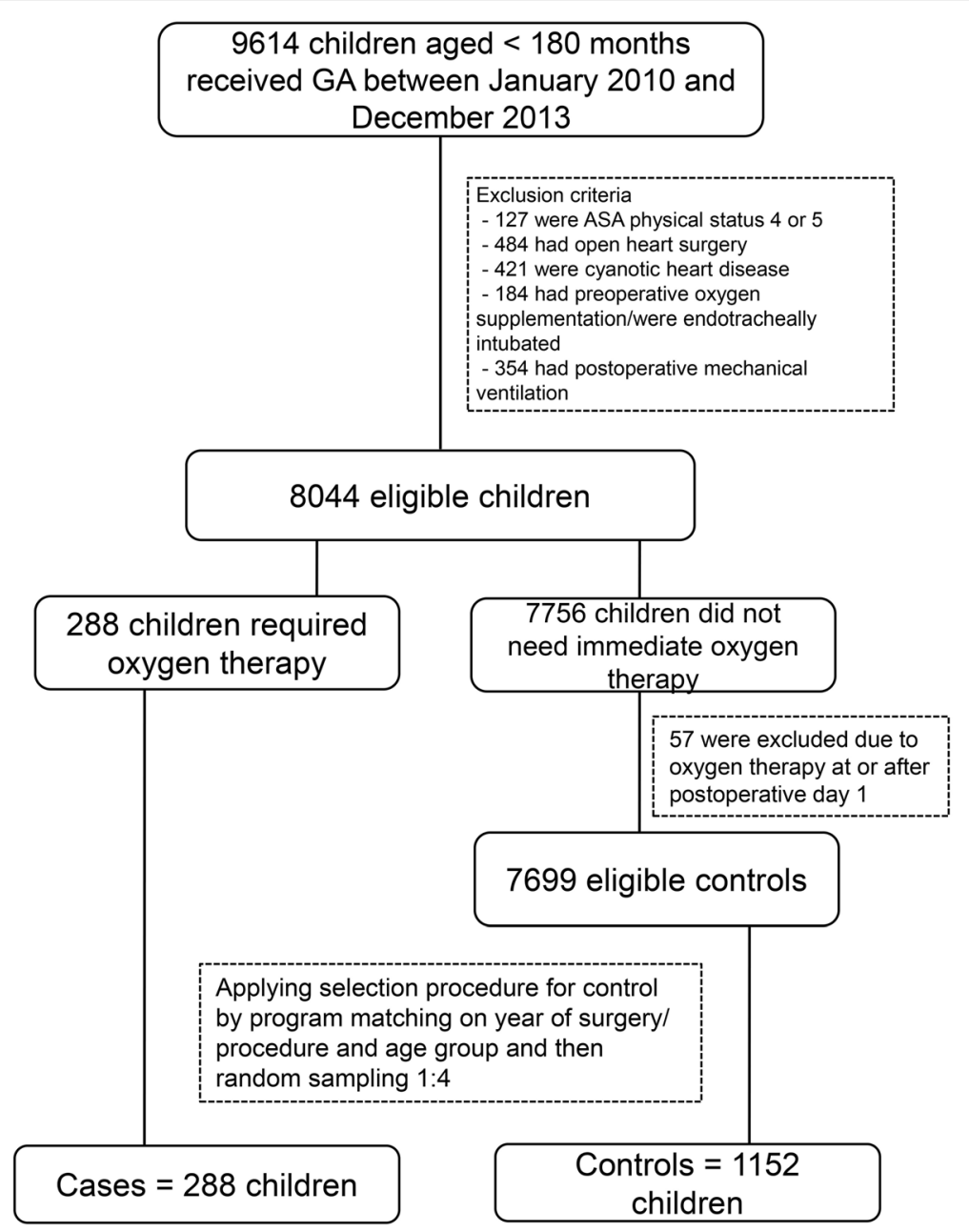

Fig. 1 Flow diagram of the study. GA General anesthesia, ASA American Society of Anesthesiologists

device, neuromuscular blocking agent used, and having a respiratory event during anesthesia (Additional file 2). Table 4 shows the results of the final hurdle model predicting duration of postoperative oxygen therapy.

\section{Discussion}

This matched case-control study determined predictors of the use and duration of postoperative oxygen therapy using a hurdle model to present two sets of predictors. A risk prediction tool for postoperative oxygen therapy was developed giving an area under the ROC curve of 0.93 . Using the risk scores obtained from the model coefficients, children were classified into high (score $\geq 12$ ), intermediate (8$11)$, or low ( $\leq 7)$ risk groups. These risk scores can be used to determine the level of need for postoperative oxygen therapy among children with similar risk factors.

\section{Risk prediction tool for postoperative oxygen therapy}

The optimal cut-point from the ROC curve was 12; therefore, we classified children with a score of $\geq 12$ as high risk. A score of 8 showed high sensitivity (98.6\%) which was consistent with a very low false negative rate (1.4\%) (Fig. 2). Therefore, we considered a risk score $<8$ to be a low risk (negative test) with a chance to require postoperative oxygen therapy $<1.4 \%$. Thus, an individual risk score between 8 and 11 was classified as intermediate risk.

\section{High risk group}

The high risk group (score $\geq 12$ ) included those who had thoracic surgery or had desaturation perioperatively. Children undergoing thoracic surgery (score of 11) usually need to be intubated with an endotracheal tube (score of 4) and are at high risk for postoperative oxygen therapy because they have a decrease of pulmonary functional residual capacity and high disturbance of cardiopulmonary function [14-16]. Provision of oxygen supplementation at the PACU and at a ward is necessary to prevent pulmonary complications. Children who had perioperative desaturation were also classified as high 
Table 3 Multivariate hurdle model of factors predicting postoperative oxygen therapy use and risk scores in children undergoing non-cardiac surgery

\begin{tabular}{|c|c|c|c|c|}
\hline Factor & Coefficient & Adjusted OR (95\% Cl) & $p$ value & Risk score \\
\hline \multicolumn{5}{|l|}{ Body mass index (Ref: 15-24.9) } \\
\hline $5-14.9$ & 0.51 & $1.66(1.07,2.58)$ & 0.024 & 1 \\
\hline $25-60$ & 1.04 & $2.82(1.30,6.11)$ & 0.009 & 2 \\
\hline \multicolumn{5}{|l|}{ Hyper-reactive airway (Ref: No) } \\
\hline Yes & 0.92 & $2.50(1.12,5.59)$ & 0.025 & 2 \\
\hline \multicolumn{5}{|l|}{ Probable difficult airway (Ref: No) } \\
\hline Yes & 1.61 & $4.99(1.74,14.32)$ & 0.003 & 3 \\
\hline \multicolumn{5}{|l|}{ ASA physical status (Ref: 1) } \\
\hline 2 & 0.31 & $1.36(0.73,2.53)$ & 0.327 & 0 \\
\hline 3 & 1.55 & $4.73(2.43,9.18)$ & $<0.001$ & 3 \\
\hline \multicolumn{5}{|l|}{ Site/ type of procedure (Ref: Eye) } \\
\hline Urologic & 1.46 & $4.32(1.39,13.41)$ & 0.01 & 3 \\
\hline Airway & 2.04 & $7.72(2.62,22.70)$ & 0.0002 & 4 \\
\hline Ear-nose-face & 0.82 & $2.27(0.60,8.52)$ & 0.22 & 0 \\
\hline Thoracic & 5.63 & $277.9(44.56,1733)$ & $<0.0001$ & 11 \\
\hline Intra-abdomen & 1.96 & $7.12(2.30,22.04)$ & 0.0007 & 4 \\
\hline Orthopedic & 1.95 & $7.00(2.30,21.33)$ & 0.0006 & 4 \\
\hline Intra-cranial & 2.01 & $7.45(1.62,34.20)$ & 0.01 & 4 \\
\hline Gastrointestinal scope & 1.23 & $3.42(0.88,13.37)$ & 0.07 & 0 \\
\hline Cardiac catheterization & 1.98 & $7.28(2.04,25.96)$ & 0.002 & 4 \\
\hline \multicolumn{5}{|l|}{ Airway device (Ref: Facemask/LMA) } \\
\hline Spontaneous breathing with non- rebreathing mask & 1.38 & $3.98(0.64,24.88)$ & 0.14 & 0 \\
\hline Endotracheal tube intubation & 1.89 & $6.64(2.54,17.32)$ & 0.0001 & 4 \\
\hline \multicolumn{5}{|l|}{ Neuromuscular blocking agent (Ref: None) } \\
\hline Succinylcholine & 0.67 & $1.95(0.92,4.13)$ & 0.080 & 0 \\
\hline Aminosteroid derivatives & 1.06 & $2.89(1.18,7.05)$ & 0.02 & 2 \\
\hline Benzylisoquinolines & 0.07 & $1.07(0.58,1.96)$ & 0.83 & 0 \\
\hline \multicolumn{5}{|l|}{ Anesthetic time (hours) (Ref: <1) } \\
\hline $1-2.9$ & 1.09 & $2.99(1.38,6.44)$ & 0.005 & 2 \\
\hline$\geq 3$ & 1.57 & $4.79(1.99,11.6)$ & 0.0005 & 3 \\
\hline \multicolumn{5}{|l|}{ PRAE (Ref: None) } \\
\hline UAO and laryngospasm & 4.12 & $61.5(14.4,262)$ & $<0.0001$ & 8 \\
\hline Desaturation & 6.18 & $481.2(177.9,1302)$ & $<0.0001$ & 12 \\
\hline Bronchospasm/wheezing & 4.53 & $92.4(29.7,288)$ & $<0.0001$ & 9 \\
\hline
\end{tabular}

Ref Reference group; OR Odds ratio, CI Confidence interval, ASA American Society of Anesthesiologists, LMA Laryngeal mask airway, UAO Upper airway obstruction, PRAE Perioperative respiratory adverse events

risk. Strategies to identify risk or develop a risk prediction tool to predict the occurrence of perioperative respiratory events would help to reduce the need for postoperative oxygen therapy $[9,13,17,18]$.

\section{Intermediate risk group}

The intermediate risk group (score of 8-11) included those who had bronchospasm, upper airway obstruction or laryngospasm perioperatively, or from a combination of patient risk factors, such as high body mass index (score of 2), history of hyper-reactive airway (score of 2), having probable difficult airway (score of 3), other types of operations (score of $0-4$ ), and anesthesia risk factors, such as ASA physical status 3 (score of 3), endotracheal tube intubation (score of 4), and anesthetic time $\geq 1 \mathrm{~h}$ (score of 2-3).

Obesity was found to be associated with the limitation of functional residual capacity and cardiovascular comorbidities 


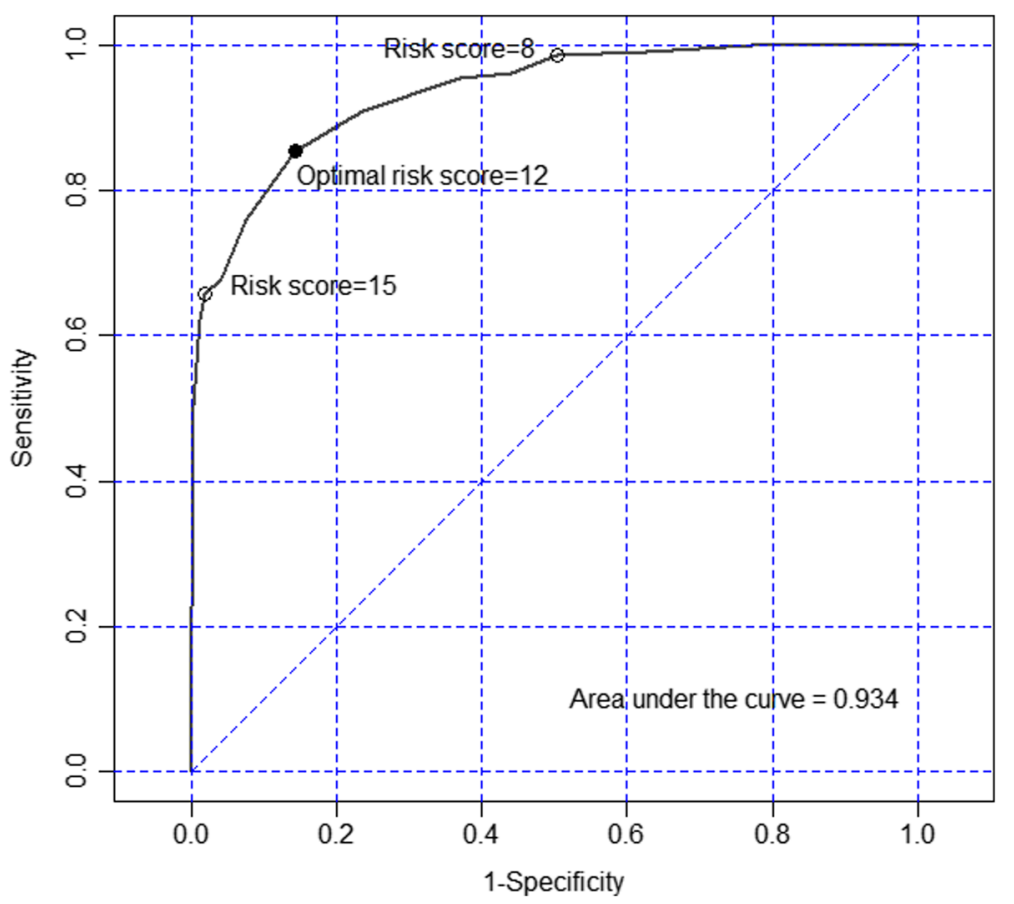

Fig. 2 Receiver operating characteristic curve of the risk score predicting postoperative oxygen therapy

that caused desaturation [13, 19-21] which may necessitate postoperative oxygen therapy. A child with a hyper-reactive airway (due to asthma) is prone to develop bronchospasm or desaturation due to airway hypersensitivity to stimuli during anesthesia. Having a probable difficult airway [22, $23]$ and prolonged anesthetic time [19, 24] may lead to the need for postoperative oxygen therapy due to upper airway obstruction, desaturation, and perioperative reintubation. The ability to quickly and easily calculate a risk score for children undergoing non-cardiac surgery might help anesthesia personnel make decisions concerning the child's management both at the preoperative and intraoperative periods. For example, if a child has an individual risk score of 6 or 7, the health personnel may try to reduce this score by preventing desaturation in difficult airway cases or by avoiding both endotracheal tube intubation and long or intermediate use of neuromuscular blocking agents intraoperatively, if feasible.

\section{Predictors for duration of postoperative oxygen therapy}

The median duration of postoperative oxygen therapy in our study was $17 \mathrm{~h}$ which is a duration that is quite safe from the harmful effects of oxygen therapy in children. The significant predictors for longer use of oxygen therapy included: history of delayed development, having probable difficult airway, thoracic, abdominal, airway and orthopedic surgery, and ASA physical status 3.

Having a probable difficult airway and airway surgery were predictors for both postoperative oxygen therapy and duration of use. Most of the children who were given oxygen via the T-piece connector $(n=11)$ had a probably difficult airway and airway surgery, thus they had a longer duration of oxygen therapy since duration (in hours) included the timing from receiving oxygen T-piece, removing endotracheal tube to weaning oxygen therapy via facemask. Children with cerebral palsy and mental retardation, defined as having delayed development, was another strong predictor for longer use of oxygen therapy (count ratio = 2.3). Most children with delayed development have several comorbidities, including cognitive disability, and have a higher risk of respiratory problems such as lower airway infection, airway secretion, or aspiration which may require longer use of postoperative oxygen therapy [25].

Compared with eye surgery, which had the lowest risk for postoperative oxygen therapy, ear-nose-face surgery and gastrointestinal endoscopy were also predictors for longer use of oxygen therapy. Ear-nose-face surgery cases included fractures of the face bones which necessitated postoperative endotracheal intubation and oxygen therapy via the T-piece connector, while children who had gastrointestinal endoscopy were more likely to have a history of delayed development. Use of morphine decreased the duration of postoperative oxygen therapy by a factor of about two-thirds compared to fentanyl. In this study, morphine was usually given $(>80 \%)$ in both older children ( $>10$ years) and those with ASA physical status 1 or 2 which may result in earlier discontinuation of postoperative oxygen therapy compared to those who received 
Table 4 Multivariate hurdle model of factors predicting duration of postoperative oxygen therapy use in children undergoing non-cardiac surgery

\begin{tabular}{lll}
\hline Factor & $\begin{array}{l}\text { Adjusted count ratio } \\
(95 \% \mathrm{Cl})\end{array}$ & $p$ value \\
\hline Probable difficult airway & $2.19(1.39,3.48)$ & 0.0008 \\
History of delayed development & $2.31(1.49,3.57)$ & 0.0002 \\
ASA physical status (Ref: 1$)$ & & $0.03^{\mathrm{a}}$ \\
2 & $0.75(0.43,1.32)$ & \\
3 & $1.07(0.61,1.88)$ & \\
Site/type of procedure (Ref: Eye) & & \\
Urologic & $1.98(0.99,3.96)$ & \\
Airway & $3.01(1.55,5.83)$ & \\
Ear-nose-face & $2.27(1.06,4.82)$ & \\
Thoracic & $4.86(2.34,10.1)$ & \\
Intra-abdomen & $4.15(2.13,8.11)$ & \\
Orthopedic & $2.14(1.08,4.25)$ & \\
Intra-cranial & $1.26(0.52,3.02)$ & \\
Gastrointestinal scope & $2.73(1.23,6.04)$ & \\
Cardiac catheterization & $1.18(0.53,2.60)$ & \\
Narcotic used (Ref: None) & & \\
Morphine & $0.049^{\mathrm{b}}$ \\
Fentanyl & $1.10(0.72,1.68)$ & \\
\hline Ref & & \\
\hline
\end{tabular}

Ref Reference group, ASA American Society of Anesthesiologists

${ }^{a}$ The contrast of ASA physical status 3 vs ASA physical status 2 gave a significant count ratio of 1.42 and $95 \% \mathrm{Cl}$ of 1.10 and 1.84 .

${ }^{\mathrm{b}}$ The contrast of morphine vs fentanyl gave a significant count ratio of 0.63 and $95 \% \mathrm{Cl}$ of 0.44 and 0.90 .

fentanyl. However, since age group was matched between cases and controls and ASA physical status was adjusted in the final model (Table 4), an explanation of this result is inconclusive as no other study has reported a similar result. Further studies focusing on opioids for postoperative oxygen therapy may help to explain this result.

Since $80 \%$ of respiratory events during anesthesia were mild desaturation $\left(\mathrm{SpO}_{2} 90-94 \%\right)$ and brief in duration (<60 s), which required oxygen therapy for a short duration $(<17 \mathrm{~h})$, it was not a predictor for duration of oxygen therapy. Thus, low flow oxygen or a lower oxygen concentration should be considered for those at high risk to reduce the risk of oxygen toxicity $[26,27]$. Therefore, we attempted to limit the fraction of inspired oxygen between 0.4 and 0.6. We also provided continuous oxygen saturation monitoring and weaned off the oxygen therapy as soon as possible in almost $25 \%$ of the children who received oxygen therapy for more than $24 \mathrm{~h}$.

Important issues and implications for clinical management Our risk prediction tools have implications for aiding physicians in their clinical decision making peri-operatively. These can be divided into four strategic steps.
First, pre-operatively, physicians can utilize the risk prediction tool to quickly calculate a risk score indicating the degree of need for post-operative oxygen therapy. For example, an obese child (score +2$)$, or one with hyperactive airway $(+2)$, history of difficult airway $(+3)$, or with an ASA physical status $3(+3)$, would have an increased risk of requiring post-operative oxygen therapy. Having multiple risk factors would also increase the requirement substantially.

Second, combining pre-operative with intra-operative risk factors can help physicians determine which children have an increased need for post-operative oxygen therapy, for example, children who undergo thoracic surgery or cardiac catheterization. In addition, children with a history of delayed development or those requiring a gastrointestinal scope may not only require post-operative oxygen therapy but may require prolonged use.

Third, children who score highly $(\geq 12)$ on pre- and intra-operative risk factors can be targeted for receiving extra attention by anesthetic personnel. On the other hand, children who have low scores $(\leq 7)$ may be given short-acting neuromuscular blocking agents, or given an anesthetic device that has a low risk of oxygen therapy postoperatively such as a laryngeal mask airway or facemask, or given shorter anesthetic time (if feasible), or tried to minimize the incidence of respiratory events during anesthesia.

Fourth, minimizing the risk of prolonged oxygen therapy, by minimizing the risk score, should also result in a reduced duration of postoperative oxygen therapy. If oxygen therapy is absolutely necessary, for example when given as a prophylaxis in high risk children or when a respiratory event occurs during anesthesia, weaning children off oxygen therapy should be considered in those who have a low $(\leq 7)$ or intermediate $(8-11)$ risk score as soon as possible when signs and symptoms of hypoxia have improved in order to minimize the consequences of excessive use of postoperative oxygen therapy [28, 29]. It has been suggested that an audit of the criteria used for prescribing oxygen such as target saturations, oxygen device used, and indication for use, would help wean children off postoperative oxygen therapy [30]. However, if the prolonged need for postoperative oxygen therapy cannot be avoided, the lowest fraction of inspired oxygen concentration $(<0.5)$ should be considered to prevent long term complications and enhance patient safety.

\section{Strengths and limitations}

This study has some strengths. Matching cases to controls was done using age groups and year of surgery to reduce selection bias and to balance the two groups in terms of age. The multivariate hurdle model to predict both outcomes (any use and duration of postoperative oxygen therapy) was performed to adjust for potential confounding 
variables. The sample size was adequate which resulted in a high area under the ROC curve (0.93).

Even though we attempted to minimize the selection bias, some information bias from the database could have occurred. The incidence of a respiratory event during anesthesia in our study as well as some patient-related factors such as snoring and URI were quite low compared to a previous prospective study [24]. Finally, the child's age, which might affect the need for postoperative oxygen therapy, could not be evaluated since it was used for matching.

Even though this was a retrospective study, the reliability and accuracy of our results are quite high because the outcomes were determined from records confirmed by two experienced anesthesiologists, the study was matched on age and year of operation, and the sample size was large. The external validity to other children in the same setting should be convincing although the subjects were recruited from a single university hospital.

\section{Conclusions}

Our risk prediction tool for postoperative oxygen therapy provided a high predictive ability and severity of risk prediction score. For both outcomes, the common risk factors were: probable difficult airway, ASA physical status 3 , and operations involving the airway, thorax, and abdomen. Anesthesia-related and surgery-related factors played an important role in the longer use of postoperative oxygen therapy. Some patient-related and surgery-related risks may not be preventable but the adjustment of oxygen therapy can be made under patient safety issues.

\section{Additional files}

Additional file 1: The distribution of the number of hours of oxygen use. (TIFF $1009 \mathrm{~kb}$ )

Additional file 2: Univariate hurdle model predicting duration of postoperative oxygen therapy use in children undergoing non-cardiac surgery $(n=1440)$. (PDF $43 \mathrm{~kb})$

\section{Abbreviations}

ASA: American Society of Anesthesiologist; PACU: Post-anesthetic care unit; ROC: Receiver operating characteristic; URI: Upper respiratory tract infection; $\mathrm{SpO}_{2}$ : Oxygen saturation by pulse oximetry

\section{Acknowledgements}

We would like to thank Assistant Professor Edward McNeil for editing the manuscript and Glenn Shingledecker for correcting some grammatical errors in the manuscript.

\section{Funding}

This work was funded by the Faculty of Medicine, Prince of Songkla

University, Hat Yai, Songkhla, Thailand.

\section{Availability of data and materials}

The datasets used and/or analysed during the current study are available from the corresponding author on reasonable request.

\section{Authors' contributions}

All those listed as authors contributed to the preparation of the manuscript. Each listed author participated in the work that they can defend its content. $\mathrm{MO}$ coordinated the study, participated in the study design, undertook the statistical analysis and wrote the draft manuscript. SR participated in its design, collected the data and revised the draft manuscript. TC participated in its design and coordinated the drafting of the manuscript. All authors have read and approved the final version.

\section{Ethics approval and consent to participate}

The study was approved by the Institutional Ethics Committee of the Faculty of Medicine, Prince of Songkla University, Songkhla, Thailand, Chairperson Assoc. Prof. Boonsin Tangtrakulwanich, EC number 57294081 on October 8, 2014 and amendment approval EC number 57294081 on February 6, 2017.

The consent to participate was not applicable.

\section{Consent for publication}

Not applicable.

\section{Competing interests}

The authors declare that they have no competing interests.

\section{Publisher's Note}

Springer Nature remains neutral with regard to jurisdictional claims in published maps and institutional affiliations.

Received: 17 October 2017 Accepted: 5 September 2018

Published online: 02 November 2018

References

1. Singh V, Gupta P, Khatana S, Bhagol A. Supplemental oxygen therapy: important considerations in oral and maxillofacial surgery. Natl J of Maxillofac Surg. 2011;2:10-4.

2. Lerman J. Perioperative respiratory complications in children. Lancet. 2010; 376:745-6.

3. von Ungern-Sternberg BS. Respiratory complications in the pediatric postanesthesia care unit. Anesthesiol Clin. 2014:32:45-61.

4. Baijal RG, Bidani SA, Minard CG, Watcha MF. Perioperative respiratory complications following awake and deep extubation in children undergoing adenotonsillectomy. Paediatr Anaesth. 2015;25:392-9.

5. Xue FS, Tong SY, Liao X, Liu JH, Zhang RJ, An G, Luo LK. Observation of the correlation of postanesthesia recovery scores with early postoperative hypoxaemia in children. Paediatr Anaesth. 1999;9:145-51.

6. Siddiqui N, Arzola C, Teresi J, Fox G, Guerina L, Friedman Z. Predictors of desaturation in the postoperative anesthesia care unit: an observational study. J Clin Anesth. 2013:25:612-7.

7. Hintong T, Klanarong S, Suksompong S, Chua-in W, Chatmongkolchat S, Werawatganon T. The Thai Anesthesia Incident Monitoring Study (Thai AIMS) of oxygen desaturation in the post-anesthetic care unit. J Med Assoc Thail. 2008;91:1531-8.

8. Kallstrom TJ. American Association for Respiratory Care (AARC).AARC clinical practice guideline: oxygen therapy for adults in the acute care facility--2002 revision \& update. Respir Care. 2002;47:717-20.

9. Oofuvong M, Geater AF, Chongsuvivatwong V, Pattaravit N, Nuanjun K. Risk over time and risk factors of intraoperative respiratory events: a historical cohort study of 14,153 children. BMC Anesthesiol. 2014;14:13. https://doi. org/10.1186/1471-2253-14-13.

10. Xue FS, Luo LK, Tong SY, Liao X, Deng XM, An G. Study of the safe threshold of apneic period in children during anesthesia induction. J Clin Anesth. 1996;8:568-74.

11. Hu MC, Pavlicova M, Nunes EV. Zero-inflated and hurdle models of count data with extra zeros: examples from an HIV-risk reduction intervention trial. Am J Drug Alcohol Abuse. 2011;37:367-75. https://doi.org/10.3109/ 00952990.2011 .597280 .

12. Neelon B, Chang HH, Ling Q, Hastings NS. Spatiotemporal hurdle models for zeroinflated count data: exploring trends in emergency department visits. Stat Methods Med Res. 2016;25:2558-76.

13. Subramanyam R, Yeramaneni S, Hossain MM, Anneken AM, Varughese AM. Perioperative respiratory adverse events in pediatric ambulatory anesthesia: development and validation of a risk prediction tool. Anesth Analg. 2016; 122:1578-85. https://doi.org/10.1213/ANE.0000000000001216. 
14. Nomori H, Kobayashi R. Postoperative pulmonary complications in patients undergoing thoracic surgery with special reference to preoperative respiratory muscle strength and nutrition. Nihon KyobuGeka Gakkai Zasshi. 1994:42:1272-5.

15. Katz LE. Postoperative complications of thoracic surgery: their recognition and treatment. AANA J. 1980;48:222-9.

16. Saito H, Minamiya Y, Kawai H, Motoyama S, Katayose Y, Kimura K, Saito R, Ogawa J. Estimation of pulmonary oxygen consumption in the early postoperative period after thoracic surgery. Anesthesia. 2007;62:648-53.

17. Tait AR, Voepel-Lewis T, Christensen R, O'Brien LM. The STBUR questionnaire for predicting perioperative respiratory adverse events in children at risk for sleep-disordered breathing. Paediatr Anaesth. 2013;23:510-6.

18. von Ungern-Sternberg BS, Boda K, Chambers NA, Rebmann C, Johnson C, Sly PD, Habre W. Risk assessment for respiratory complications in pediatric anesthesia: a prospective cohort study. Lancet. 2010;376:773-83.

19. Oofuvong M, Geater AF, Chongsuvivatwong V, Pattaravit N, Nuanjun K Association between intraoperative and post-anesthetic care unit respiratory events among 12,641 children in southern Thailand. BJMMR. 2015;6:1101-12

20. Uakritdathikarn T, Chongsuvivatwong V, Geater AF, Vasinanukorn M, Thinchana S, Klayna S. Perioperative desaturation and risk factors in general anesthesia. J Med Assoc Thail. 2008;91:1020-9.

21. Tait AR, Voepel-Lewis T, Burke C, Kostrzewa A, Lewis I. Incidence and risk factors for perioperative adverse respiratory events in children who are obese. Anesthesiology. 2008;108:375-80

22. Oofuvong $M$, Valois T, Withington DE. Laryngeal mask airway and difficult airway management in adolescent: a case report. Paediatr Anaesth. 2008;18: 1228-9. https://doi.org/10.1111/j.1460-9592.2008.02724.x.

23. Chanchayanon T, Suraseranivongse S, Chau-in W. The Thai Anesthesia Incidents Study (THAI Study) of difficult intubation: a qualitative analysis. J Med Assoc Thail. 2005;88(Suppl 7):S62-8.

24. Oofuvong M, Geater AF, Chongsuvivatwong V, Chanchayanon T, Sriyanaluk B, Saefung B, Nuanjun K. Excess costs and length of hospital stay attributable to perioperative respiratory events in children. Anesth Analg. 2015;120:411-9.

25. Proesmans M, Vreys M, Huenaerts E, Haest E, Coremans S, Vermeulen F, Feys H. Respiratory morbidity in children with profound intellectual and multiple disability. Pediatr Pulmonol. 2015;50:1033-8.

26. Milési C, Boubal M, Jacquot A, Baleine J, Durand S, Odena MP, Cambonie G. Highflow nasal cannula: recommendations for daily practice in pediatrics. Ann Intensive Care. 2014;4:29. https://doi.org/10.1186/s13613-014-0029-5 eCollection 2014.

27. AARC. AARC clinical practice guideline. Oxygen therapy in the home or alternate site health care facility--2007 revision \& update. Respir Care. 2007; 52:1063-8.

28. Yeh J, McGrath-Morrow SA, Collaco JM. Oxygen weaning after hospital discharge in children with bronchopulmonary dysplasia. Pediatr Pulmonol. 2016;51:1206-11. https://doi.org/10.1002/ppul.23442.

29. Jindal SK. Oxygen therapy: important considerations. Indian J Chest Dis Allied Sci. 2008;50:97-107.

30. Wheeler L, James J, Byrne S, Forton J. Audit of oxygen prescribing in a children's hospital. Arch Dis Child. 2016;101:e2. https://doi.org/10.1136/ archdischild-2016-311535.36.

Ready to submit your research? Choose BMC and benefit from:

- fast, convenient online submission

- thorough peer review by experienced researchers in your field

- rapid publication on acceptance

- support for research data, including large and complex data types

- gold Open Access which fosters wider collaboration and increased citations

- maximum visibility for your research: over $100 \mathrm{M}$ website views per year

At BMC, research is always in progress.

Learn more biomedcentral.com/submissions 